\title{
Sedative load and salivary secretion and xerostomia in community-dwelling older people
}

\author{
Antti Tiisanoja ${ }^{1}$, Anna-Maija Syrjälä ${ }^{1,2}$, Kaija Komulainen ${ }^{3,4}$, Sirpa Hartikainen ${ }^{5,6}$, Heidi Taipale ${ }^{5,6}$, \\ Matti Knuuttila ${ }^{1}$, Pekka Ylöstalo ${ }^{1,7,8,9}$
}

Running title: Sedative load and dry mouth in older people

Keywords: aged, independent living, medication, salivation, xerostomia,

${ }^{1}$ Department of Periodontology and Geriatric dentistry, Institute of Dentistry, University of Oulu, Finland

${ }^{2}$ Dental training clinic, Social and Health services, City of Oulu, Oulu, Finland

${ }^{3}$ School of Pharmacy, University of Eastern Finland, Kuopio, Finland

${ }^{4}$ Social and Health Centre of Kuopio, Kuopio, Finland

${ }^{5}$ Department of Social Pharmacy, School of Pharmacy, University of Eastern Finland, Kuopio, Finland

${ }^{6}$ Unit of Clinical Pharmacology and Geriatric Pharmacotherapy, School of Pharmacy, University of Eastern Finland,

Kuopio, Finland

${ }^{7}$ Institute of Dentistry, University of Eastern Finland, Kuopio, Finland

${ }^{8}$ Oral and Maxillofacial Department, Oulu University Hospital, Oulu, Finland

${ }^{9}$ Department of Oral and Maxillofacial Diseases, Kuopio University Hospital, Kuopio, Finland

Corresponding author:

Antti Tiisanoja

Department of Periodontology and Geriatric Dentistry

Institute of Dentistry

P.O. BOX 5281

FI-90401, University of Oulu

Finland

antti.tiisanoja@student.oulu.fi 


\section{ABSTRACT}

Objective: The aim was to investigate how sedative load and the total number of drugs used are related to hyposalivation and xerostomia among 75-year-old or older dentate, non-smoking, community-dwelling people.

Materials and Methods: The study population consisted of 152 older people from the Oral Health GeMS study. The data were collected by interviews and clinical examinations during 2004-2005. Sedative load, which measures the cumulative effect of taking multiple drugs with sedative properties, was calculated using the Sedative Load Model.

Results: The results showed that participants with a sedative load of either $1-2$ or $\geq 3$ had an increased likelihood of having low stimulated salivary flow $(<0.7 \mathrm{ml} / \mathrm{min})(\mathrm{OR}: 2.4$; CI: 0.6-8.6 and OR: 11; CI: 2.2-59; respectively) and low unstimulated salivary flow (<0.1 $\mathrm{ml} / \mathrm{min})$ (OR: 2.7 , CI: 1.0-7.4 and OR: 4.5, CI: 1.0-20, respectively) compared to participants without a sedative load. Participants with a sedative load $\geq 3$ had an increased likelihood of having xerostomia (OR: 2.5, CI: 0.5-12) compared to participants without a sedative load. The results showed that the association between the total number of drugs and hyposalivation was weaker than the association between sedative load and hyposalivation.

Conclusion: Sedative load is strongly related to hyposalivation and to a lesser extent with xerostomia. The adverse effects of drugs on saliva secretion are specifically related to drugs with sedative properties. 


\section{INTRODUCTION}

Due to biological changes in the body older people are more susceptible to the adverse effects of medications than younger individuals. These changes affect the distribution, metabolism and excretion of drugs. One of the commonest side-effects caused by medication especially psychotropic drugs is hyposalivation. This is due to their anticholinergic side-effects on muscarinic receptors ${ }^{1}$.

Use of drugs with sedative properties is frequent among older people ${ }^{2,3}$, ranging from 10 to 40 percent of the older population ${ }^{3-5}$. In addition, older patients often use multiple drugs with sedative properties simultaneously, and therefore it is important to study the cumulative effects of multiple drugs with sedative properties on salivary secretion and xerostomia. The knowledge related to adverse effects of medication is not at a sufficient level although earlier studies have shown that different medications ${ }^{6,7}$ and simultaneous use of at least four whatever drugs ${ }^{8}$ are related to hyposalivation or xerostomia. To our knowledge, only one study has focused on the relation between simultaneous use of multiple drugs with sedative properties (antidepressants and benzodiazepams) and hyposalivation ${ }^{9}$. That study showed that simultaneous use of antidepressants and benzodiazepams lowers stimulated salivary flow more than use of antidepressants alone ${ }^{9}$.

Drugs such as opioids, anticonvulsants, antidepressants, antipsychotics and anxiolytics all have sedative properties, either as a wanted or an unwanted effect. Cumulative exposure to these drugs is called sedative load (SL), which can be measured by using the Sedative Load Model, a numeric presentation of sedation caused by medication ${ }^{10}$. Subsequently, the first aim of this paper was to study whether sedative load is related to stimulated and unstimulated salivary secretion and xerostomia among community-dwelling older people. Our second aim was to compare the effect of sedative load and the total number of drugs on hyposalivation and xerostomia.

\section{MATERIALS AND METHODS}


In this study we used data from the Oral Health GeMS (Geriatric Multidisciplinary Strategy for the Good Care of the Elderly) study, which is part of a larger GeMS study consisting of randomly selected subjects 75 years of age or older on November 1, 2003. We restricted our study population to community-dwelling, non-smoking, dentate people (at least one clinically visible tooth or root of the tooth), whose sedative load was measured $n=152$ (109 women and 43 men; mean age 79.4).

Written informed consent was obtained from the participants or their relatives and the study protocol was approved by the ethics committee of Kuopio University Hospital and the University of Kuopio. The GeMS ${ }^{11,12}$ and Oral Health GeMS ${ }^{13,14}$ studies have been described in more detail in previous papers.

\section{Comprehensive Geriatric Assessment (CGA)}

A comprehensive geriatric assessment was performed on all the participants of this study. Information about each participant's health status and health behavior was obtained by interview and a clinical examination done by a multidisciplinary team including nurses, physiotherapists and physicians specializing in geriatrics. In situations where the participant was unable to answer the questions due to his/her cognitive or other impairment, a close relative or a caregiver provided the information. If the participant was unable to visit the local municipal health centre, the interviewer and a physician made a home visit to conduct the interview and clinical examination. Medical records from local municipal centres, home-nursing services, local hospitals and Kuopio University Hospital were used in the GeMS study.

\section{Clinical oral examination}

The clinical oral examinations and oral health interviews were carried out by dentists during 20042005. Before collecting the data, the dentists were trained by examining seven patients together. The oral examinations were performed in a dental unit using a WHO color-coded periodontal probe, a mouth mirror and a gauze pad. If the participant was uncomfortable with or unable to visit the 
local dental clinic, a home visit was made by a dentist together with a dental nurse or oral hygienist. Because of the high age of the participants and the length of clinical examination, no repeated or parallel examinations were performed.

\section{Outcome variables}

Unstimulated and stimulated salivary secretion rates and xerostomia were used as outcome variables. All the participants provided unstimulated and stimulated saliva samples and they answered questions about xerostomia. The participants were asked to refrain from eating or drinking one hour before the unstimulated and stimulated salivary flow rates were measured. If the participant had removable dentures, the unstimulated saliva was collected without dentures and the stimulated saliva with dentures.

The draining method was used to measure unstimulated salivary flow ${ }^{15}$. In order to measure unstimulated salivary flow, the participants were instructed to sit straight and bend their head slightly forward. First the participant was asked to swallow, and then to drool saliva for five minutes into a centrifuge tube. The collection of stimulated saliva began with the participant chewing a paraffin wax capsule for 30 seconds and then swallowing or spitting the saliva. After clearing the mouth of the first saliva, the participant was asked to chew the paraffin capsule again for five minutes and the saliva stimulated by mastication was drained into a glass centrifuge tube.

The stimulated salivary secretion rate was categorized in two ways: first, $<0.7 \mathrm{ml} / \mathrm{min}$ (low) $v s$. $\geq$ $0.7 \mathrm{ml} / \mathrm{min}$ (normal) and second, $<1.0 \mathrm{ml} / \mathrm{min}$ (low) $v s . \geq 1.0 \mathrm{ml} / \mathrm{min}$ (normal). The unstimulated salivary secretion rate was also classified into two categories: $<0.1 \mathrm{ml} / \mathrm{min}$ (low) $v s . \geq 0.1 \mathrm{ml} / \mathrm{min}$ (normal). The cut-off values were based on the literature ${ }^{16,17}$. Xerostomia was classified into two categories based on the frequency of a feeling of dry mouth: no or occasional feeling of dry mouth vs. often feelings of dry mouth.

\section{Explanatory variable}


The participant's self-reported drug use was asked during an interview by a study nurse in 2004, on average six months before the clinical oral examination. Self-reported drug use was verified from prescription forms and drug packages and medical records provided by the municipal health centre, home-nursing services, local hospitals and Kuopio University Hospital. Sedative load was used as an explanatory variable and it was calculated for each participant by using the Sedative Load Model, specially designed for older people ${ }^{3,10}$. The model was updated in 2009 to include drugs which have been marketed in Finland since the development of the original model ${ }^{18}$. In this model, each drug used by the participants was categorized into one of four groups based on the drug's sedative properties. The first group included the first line of sedative drugs (e.g. anxiolytics, hypnotics, conventional antipsychotics, tricyclic antidepressants) and the second group included drugs with sedation as a prominent side-effect and drugs with a sedating component (e.g. SSRIs, atypical antipsychotics, anticonvulsants). The third group consisted of drugs with sedation as a potential but rare adverse drug reaction (e.g. second-generation antihistamines, acetylcholinesterase inhibitors). The fourth group included all other drugs with no known sedative properties.

A sedative rating was assigned to each of the four groups of drugs based on their sedative properties. In group one all the drugs were given a numeric rating of 2 and in group two the drugs were given a rating of 1 . The drugs in groups three and four were given a rating of 0 . To determine each participant's sedative load, all the ratings of the drugs which the participant used regularly were summed using the following formula:

$$
\text { Sedative load: } S L=\sum_{k=1}^{n} S R_{k}
$$

$\mathrm{n}$ stands for the number of drugs and $\mathrm{SR}_{\mathrm{k}}$ is the sedative rating of drug $\mathrm{k}$.

Sedative load was categorized into three groups: 1) 0 , 2) 1-2 (moderate) and 3) $\geq 3$ (high). Details 
of sedative load in the GeMS study have been described previously ${ }^{18}$.

The total number of drugs used was obtained from the interview by a study nurse and it included the participant's regularly used drugs, when-required drugs and supplementary vitamins. The total number of drugs was used as both a classified variable $(0-3,4-6,7-9, \geq 10)$ and a continuous variable.

\section{Other variables}

Visits to a dental clinic were classified into two categories: regularly vs. symptom-based or never. The participants' toothbrushing frequency was also classified into two categories: at least twice a day vs. more seldom.

The functional ability of the participants was assessed using the Instrumental Activities of Daily Living scale (IADL) ${ }^{19}$. The IADL questionnaire was comprised of eight fields of daily activities. The IADL score ranged among the participants from 0 (inability) to 8 (high ability) and it was categorized into two groups: 0-6 vs. 7-8.

Diagnoses of diabetes and rheumatoid diseases (arthritis, polymyalgia rheumatica, Sjörgen's syndrome, other rheumatoid disease) were determined from information obtained from the CGA examination, from medical records in primary health care or Kuopio University Hospital, or from data obtained from the Finnish Special Reimbursement Registers maintained by the Social Insurance Institution of Finland.

\section{Statistical methods}

Logistic regression models were used to estimate odds ratios (OR) and 95\% confidence intervals (CI). The models were adjusted for confounding factors such as age, gender, education, diabetes and rheumatoid diseases. The second model for SL was further adjusted for the total number of drugs used by the patient. The statistical analyses were done with SPSS 20.0 software for Windows ${ }^{20}$. 


\section{RESULTS}

The characteristics of the participants according to the categories of sedative load are presented in Table 1. Unadjusted odds ratios for explanatory variables are shown in Table 2. Box-plot graphs for both stimulated and unstimulated salivary flow and sedative load are presented in Figure 1. From Figure 1 it can be seen that the higher SL is, the lower stimulated and unstimulated salivary flows are, despite considerable individual variation.

The results of the regression models are presented in Table 3. After adjustment for confounding factors, subjects with either SL 1-2 or SL $\geq 3$ were more likely to have low stimulated salivary flow (<1.0 ml/min) (OR: 1.2, CI: 0.4-3.3 and OR: 4.8, CI: 0.9-24, respectively) compared to the reference group, i.e., subjects with no sedative load (SL 0). Continuous SL provided the following odds ratio: 1.29 (0.9-1.86). Additional adjustments for the subjects' total number of drugs did not change the odds ratios essentially (Table 3).

Subsequent analysis was done using a lower cut-off value for stimulated salivary flow $(<0.7$ $\mathrm{ml} / \mathrm{min}$ ) and it was found that the odds ratios were higher than when using $1.0 \mathrm{ml} / \mathrm{min}$ as a cut-off value. The corresponding odds ratios were 2.4 (CI: 0.6-8.6) for SL 1-2 and 11 (CI: 2.2-59) for SL $\geq 3$. The odds ratio for continuous SL was 1.84 (1.19-2.82). When these models were adjusted for the subjects' total number of drugs, it was found that the odds ratios attenuated slightly (Table 3, Model 2).

Besides an increased likelihood of having low stimulated salivary flow, subjects with a sedative load were also more likely to have low unstimulated salivary flow $(<0.1 \mathrm{ml} / \mathrm{min})(\mathrm{OR}: 2.7$, CI: 1.0 7.4, for SL 1-2 and OR: 4.5, CI: 1.0-20, for SL $\geq 3$ ) compared to the reference group. The odds ratio for continuous SL was 1.51 (1.05-2.17). After additional adjustment for the subjects' total number of drugs, the odds ratios attenuated only slightly (Table 3, Model 2).

When xerostomia was used as the outcome, it was found that subjects with SL 1-2 had an OR of 0.7 
(CI: 0.2-2.3) and subjects with SL $\geq 3$ had an OR of 2.5 (CI: 0.5-12) compared to the reference group, respectively. The odds ratio for continuous SL was $1.04(0.72-1.51)$. Further adjustment for the subjects' total number of drugs somewhat lowered the risk estimates (Table 3, Model 2).

We also did additional analyses where we used the total number of drugs as an explanatory variable. These analyses showed that the association between the total number of drugs and hyposalivation was weaker than the association between sedative load and hyposalivation (Table 3). Spearman's correlation of sedative load and total number of drugs was $0.402, \mathrm{p}>0.001$.

\section{DISCUSSION}

The commonest ways medications cause salivary dysfunction are through inhibition of acethylcholine binding to muscarinic receptors or by affecting other receptors $(\alpha 1 / \beta 1, H 2$, GABA, etc.) on acinar cells ${ }^{1,21}$. Medications which are thought to act this way include tricyclic antidepressants, hypnotics/sedatives, antihistamines and anticonvulsant drugs. Previous studies 6,7 have shown that these drugs are associated with low stimulated salivary secretion, and it has also been found that concomitant use of multiple drugs may have an additive effect on salivary secretion and cause severe hyposalivation and xerostomia ${ }^{8,22}$.

According to our knowledge, the effect of drug use on hyposalivation has not been studied by using a measurement that determines the sedative load caused by overall drug use. Admittedly, the finding that sedative load is associated with hyposalivation is by no means unexpected for the abovementioned reasons. The results are also in line with previous studies which have shown an association between the use of drugs with sedative properties and hyposalivation ${ }^{1,6,9}$. However, this study suggests that concomitant use of multiple drugs per se is not an essential risk for hyposalivation, but the findings lend support to the conception that hyposalivation is especially attributed to use of drugs with sedative properties. This is also supported by the fact that the models which used sedative load as explanatory variable showed essentially higher odds ratios and behaved 
in a more coherent manner than the ones using the total number of drugs.

It is worth emphasizing that the Sedative Load Model measures the cumulative effect of taking multiple drugs with sedative properties, including also drugs with sedation as a side-effect - for example, drugs which are prescribed for somatic disorders. The validity of the Sedative Load Model as a measure of cumulative exposure to drugs with sedative properties in older people has been documented in a earlier study ${ }^{23}$.

In this study, we restricted the study population to community-dwelling, non-smoking older people, which, on one hand, meant that the confounding effects of smoking, age and physical capacity were reduced or totally eliminated. We also controlled for the effects of gender, education and common diseases that are known to be associated with hyposalivation and xerostomia — such as diabetes and rheumatoid diseases - by using multivariate models. Of course, despite our efforts to control for confounding factors, the possibility of residual confounding could not be totally excluded. For example, anxiety and stress ${ }^{24,25}$ are known to cause hyposalivation and xerostomia but it was not possible to take these factors into account due to a lack of relevant data. None of the subjects had HCV-, HIV- or radiotherapy-induced xerostomia. The disadvantage of controlling for the effect of smoking and physical capacity by restrictions, which were made in order to increase the validity of the study, meant that the study population became smaller. This, small study population, is of course one of the limitations of this study.

Hyposalivation decreases the quality of life by making speaking, masticating and tasting difficult and by causing or contributing to a subjective sensation of dry mouth ${ }^{26}$. Hyposalivation also contributes to oral diseases such as dental caries and prosthetic stomatitis ${ }^{27}$. The findings stress the importance of measuring salivary flow from patients who use multiple drugs with sedative properties, in order to detect those who are at risk of hyposalivation.

\section{CONCLUSION}


Sedative load is strongly related to hyposalivation and to a lesser extent with xerostomia. The adverse effects of drugs on saliva secretion are specifically related to drugs with sedative properties.

\section{ACKNOWLEDGEMENTS}

The GeMS study has been supported by the Social Insurance Institute and the City of Kuopio. A personal grant was given to Antti Tiisanoja by the August \& Lyydia Heino Foundation. We thank Paula Pesonen for her statistical guidance. 
Table 1. Characteristics of the participants by different categories of sedative load.

\begin{tabular}{|c|c|c|c|}
\hline \multirow[t]{2}{*}{ Characteristics } & \multicolumn{3}{|c|}{ Sedative load ${ }^{\mathrm{a}}$} \\
\hline & 0 & $1-2$ & $\geq 3$ \\
\hline $\mathrm{N}$ & 110 & 31 & 11 \\
\hline Age $($ mean $\pm \mathrm{SD})$ & $78.9 \pm 3.7$ & $80.8 \pm 3.5$ & $79.8 \pm 3.3$ \\
\hline$\geq 85$ years, $n(\%)$ & $7(6)$ & $4(13)$ & 0 \\
\hline Gender, proportion of women, $\mathrm{n}(\%)$ & $72(66)$ & $27(87)$ & $10(91)$ \\
\hline Education $\geq 7$ years, $\mathrm{n}(\%)$ & $64(58)$ & $17(55)$ & $5(50)^{b}$ \\
\hline Number of teeth (mean \pm SD) & $15.4 \pm 8.0$ & $13.8 \pm 8.0$ & $15.5 \pm 9.0$ \\
\hline $\begin{array}{l}\text { Number of teeth with periodontal pockets } \geq 4 \mathrm{~mm} \\
(\text { mean } \pm \text { SD) }\end{array}$ & $2.8 \pm 3.5$ & $2.9 \pm 5.1$ & $1.6 \pm 2.0$ \\
\hline Number of carious teeth (mean \pm SD) & $0.9 \pm 1.3$ & $1.6 \pm 2.5$ & $2.8 \pm 4.8$ \\
\hline \multicolumn{4}{|l|}{ Self-reported dry mouth } \\
\hline No or occasional, n (\%) & $89(81)$ & $24(77)$ & $6(55)$ \\
\hline Often, n (\%) & $21(19)$ & $7(23)$ & $5(45)$ \\
\hline \multicolumn{4}{|l|}{ Stimulated salivary flow } \\
\hline Mean $\pm \mathrm{SD}(\mathrm{ml} / \mathrm{min})$ & $1.4 \pm 0.7$ & $1.1 \pm 0.7$ & $0.7 \pm 0.6$ \\
\hline$<0.7 \mathrm{ml} / \mathrm{min}, \mathrm{n}(\%)$ & $13(12)$ & $10(32)$ & $7(64)$ \\
\hline$\geq 0.7 \mathrm{ml} / \mathrm{min}, \mathrm{n}(\%)$ & $97(88)$ & $21(68)$ & $4(36)$ \\
\hline$<1.0 \mathrm{ml} / \mathrm{min}, \mathrm{n}(\%)$ & $24(22)$ & $14(45)$ & $8(72)$ \\
\hline$\geq 1.0 \mathrm{ml} / \mathrm{min}, \mathrm{n}(\%)$ & $86(78)$ & $17(55)$ & $3(28)$ \\
\hline \multicolumn{4}{|l|}{ Unstimulated salivary flow } \\
\hline Median (ml/min) & 0.4 & 0.1 & 0.0 \\
\hline$<0.1 \mathrm{ml} / \mathrm{min}, \mathrm{n}(\%)$ & $24(22)$ & $15(48)$ & $6(55)$ \\
\hline$\geq 0.1 \mathrm{ml} / \mathrm{min}, \mathrm{n}(\%)$ & $86(78)$ & $16(52)$ & $5(45)$ \\
\hline \multicolumn{4}{|l|}{ Dental plaque } \\
\hline$\leq 20 \%$ of teeth with dental plaque, $\mathrm{n}(\%)$ & $42(38)$ & $9(29)$ & $2(18)$ \\
\hline $21-50 \%$ of teeth with dental plaque, $\mathrm{n}(\%)$ & $26(24)$ & $10(32)$ & $2(18)$ \\
\hline$>50 \%$ of teeth with dental plaque, $\mathrm{n}(\%)$ & $42(38)$ & $12(39)$ & $7(64)$ \\
\hline \multicolumn{4}{|l|}{ Dental calculus } \\
\hline$\leq 20 \%$ of teeth with dental calculus, $\mathrm{n}(\%)$ & $27(25)^{\mathrm{b}}$ & $10(32)$ & $4(36)$ \\
\hline $21-50 \%$ of teeth with dental calculus, $\mathrm{n}(\%)$ & $38(35)^{\mathrm{b}}$ & $9(29)$ & $2(18)$ \\
\hline$>50 \%$ of teeth with dental calculus, $\mathrm{n}(\%)$ & $44(40)^{\mathrm{b}}$ & $12(39)$ & $5(46)$ \\
\hline Toothbrushing at least twice a day, $\mathrm{n}(\%)$ & $93(85)$ & $25(83)^{b}$ & $9(82)$ \\
\hline
\end{tabular}


Regularly dental visits, n (\%)

Consumption of sweets, weekly or more often, $\mathrm{n}(\%)$

Consumption of sweet drinks, weekly or more often, $\mathrm{n}$

(\%)

Diabetes, n $(\%)$

$\mathrm{BMI} \geq 30, \mathrm{n}(\%)$

Rheumatoid diseases, $\mathrm{n}(\%)$

MMSE (mean $\pm \mathrm{SD})$

IADL 0-6, n (\%)

Total number of drugs (mean $\pm \mathrm{SD}$ )

$\begin{array}{lll}67(61) & 17(57)^{\mathrm{b}} & 6(55) \\ 47(43) & 11(35) & 6(55) \\ 86(78) & 18(58) & 8(73)\end{array}$

$10(9) \quad 6(19) \quad 2(18)$

$23(21) \quad 6(19) \quad 4(36)$

$16(16)^{\mathrm{d}} \quad 0^{\mathrm{c}} \quad 1(9)$

$28 \pm 2.8 \quad 26 \pm 3.7 \quad 26 \pm 4.2$

$16(15)^{\mathrm{b}} \quad 9(29) \quad 7(64)$

$5.7 \pm 3.6 \quad 8.9 \pm 4.5 \quad 9.8 \pm 2.9$

\footnotetext{
${ }^{\mathrm{a}}$ Linjakumpu et. al $(2003,2004),{ }^{\mathrm{b}}$ one participant missing, ${ }^{\mathrm{c}}$ two participants missing, ${ }^{\mathrm{d}}$ ten participants missing.

BMI; Body Mass Index, MMSE; Mini-Mental State Examination, IADL; Instrumental Activities of Daily Living.
} 
Table 2. Characteristics of participants associated with stimulated and unstimulated salivary flow and xerostomia.

\begin{tabular}{|c|c|c|c|}
\hline \multirow{3}{*}{ Characteristics } & \multicolumn{2}{|c|}{ Salivary flow } & \multirow[t]{2}{*}{ Xerostomia } \\
\hline & $\begin{array}{c}\text { Stimulated } \\
(<1.0 \mathrm{ml} / \mathrm{min})\end{array}$ & $\begin{array}{l}\text { Unstimulated } \\
(<0.1 \mathrm{ml} / \mathrm{min})\end{array}$ & \\
\hline & OR (CI 95\%) & OR (CI 95\%) & OR (CI 95\%) \\
\hline \multicolumn{4}{|l|}{ Sedative load } \\
\hline 0 & 1.0 & 1.0 & 1.0 \\
\hline $1-2$ & $2.4(1.1-5.5)$ & $3.4(1.5-7.8)$ & $1.2(0.5-3.3)$ \\
\hline$\geq 3$ & $7.8(1.9-31)$ & $4.3(1.2-15)$ & $3.5(1.0-13)$ \\
\hline Age, continuous & $1.16(1.05-1.28)$ & $1.07(0.98-1.18)$ & $1.03(0.93-1.14)$ \\
\hline \multicolumn{4}{|l|}{ Gender } \\
\hline Men & 1.0 & 1.0 & 1.0 \\
\hline Women & $3.4(1.4-8.2)$ & $3.4(1.3-8.9)$ & $1.6(0.6-4.0)$ \\
\hline \multicolumn{4}{|l|}{ Education } \\
\hline$>7$ years & 1.0 & 1.0 & 1.0 \\
\hline$<7$ years & $1.0(0.5-2.0)$ & $0.8(0.4-1.7)$ & $0.4(0.5-0.9)$ \\
\hline \multicolumn{4}{|l|}{ Diabetes } \\
\hline No & 1.0 & 1.0 & 1.0 \\
\hline Yes & $5.1(1.8-14)$ & $3.5(1.3-9.7)$ & $4.6(1.6-13)$ \\
\hline \multicolumn{4}{|l|}{ Rheumatoid disease } \\
\hline No & 1.0 & 1.0 & 1.0 \\
\hline Yes & $0.8(0.3-2.4)$ & $1.4(0.5-4.0)$ & $0.8(0.2-2.8)$ \\
\hline \multicolumn{4}{|c|}{ Total number of drugs } \\
\hline $0-3$ & 1.0 & 1.0 & 1.0 \\
\hline $4-6$ & $0.8(0.3-2.2)$ & $1.4(0.5-4.3)$ & $1.0(0.2-4.0)$ \\
\hline $7-9$ & $2.3(0.8-6.4)$ & $3.3(1.0-10)$ & $3.8(1.0-14)$ \\
\hline$\geq 10$ & $2.1(0.8-5.6)$ & $5.1(1.7-15)$ & $5.8(1.7-20)$ \\
\hline continuous & $1.13(1.03-1.24)$ & $1.22(1.09-1.35)$ & $1.24(1.11-1.38)$ \\
\hline
\end{tabular}

Unadjusted odds ratio (OR) with 95\% confidence interval (CI 95\%). 
Table 3. Associations between sedative load and lowered stimulated salivary flow, unstimulated salivary flow and xerostomia.

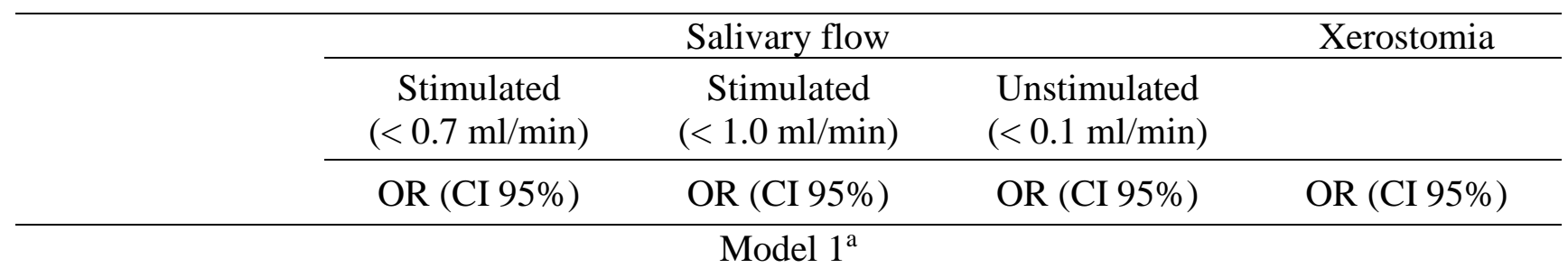

Sedative load

0

1.0

1.0

1.0

1.0

$1-2$

$2.4(0.6-8.6)$

$1.2(0.4-3.3)$

$2.7(1.0-7.4)$

$0.7(0.2-2.3)$

$\geq 3$

$11(2.2-59)$

$4.8(0.9-24)$

4.5 (1.0-20)

$2.5(0.5-12)$

continuous

$1.84(1.19-2.83)$

$1.29(0.90-1.86)$

$1.51(1.05-2.17)$

$1.04(0.72-1.51)$

\section{Model $2^{\mathrm{b}}$}

Sedative load
0
1.0
1.0
1.0
1.0
$1-2$
$2.0(0.5-7.7)$
$1.4(0.5-4.1)$
$2.5(0.9-7.0)$
$0.4(0.1-1.6)$
$\geq 3$
$9.2(1.7-51)$
$5.8(1.1-31)$
$3.9(0.8-18)$
$1.5(0.3-7.4)$
continuous
$1.73(1.09-2.74)$
$1.38(0.92-2.05)$
$1.43(0.97-2.11)$
$0.89(0.60-1.32)$

Total number of drugs ${ }^{\mathrm{c}}$
0-3
1.0
1.0
1.0
1.0
4-6
$0.7(0.1-3.9)$
$0.8(0.3-2.3)$
$1.1(0.3-3.5)$
$1.1(0.3-4.5)$
7-9
$1.2(0.2-6.7)$
$1.3(0.4-4.6)$
$2.3(0.6-8.1)$
$3.8(0.9-16)$
$\geq 10$
$1.9(0.4-9.6)$
$0.8(0.2-2.8)$
$1.6(0.4-5.8)$
$4.3(0.9-19)$
continuous
$1.10(0.96-1.27)$
$0.99(0.88-1.11)$
$1.08(0.95-1.22)$
$1.16(1.02-1.33)$

Adjusted odds ratio (OR) with 95\% confidence interval (CI 95\%).

${ }^{\text {a }}$ Adjusted for age, gender, education, diabetes and rheumatoid diseases.

${ }^{\mathrm{b}}$ Adjusted for all the above mentioned factors and also for the participant's total number of drugs.

${ }^{\mathrm{c}}$ Adjusted for age, gender, education, diabetes, rheumatoid diseases and sedative load. 
Figure 1. Box-plot graphs of both stimulated and unstimulated salivary flow and sedative load.
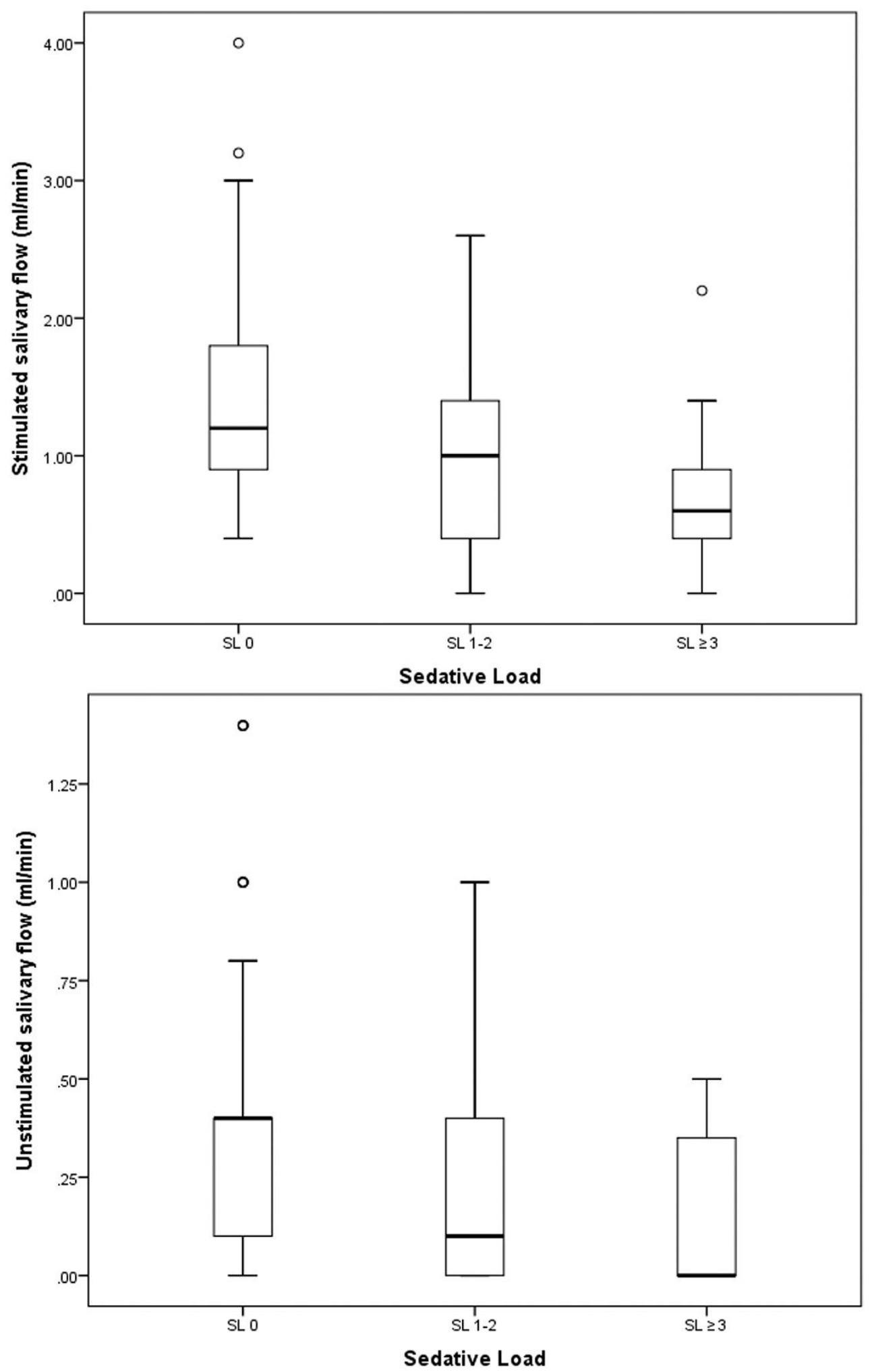


\section{References}

1. Scully C. Drug effects on salivary glands: dry mouth. Oral Dis 2003; 9:165-176.

2. Linjakumpu T, Hartikainen S, Klaukka T, Koponen H, Kivelä SL, Isoaho R. Psychotropics among the home-dwelling elderly--increasing trends. Int J Geriatr Psychiatry 2002; 17:874-883.

3. Linjakumpu TA, Hartikainen SA, Klaukka TJ, Koponen HJ, Hakko HH, Viilo KM et al. Sedative drug use in the home-dwelling elderly. Ann Pharmacother 2004; 38:2017-2022.

4. Beck CA, Williams JV, Wang JL, Kassam A, El-Guabaly N, Currie SR et al. Psychotropic medication use in Canada. Can J Psychiatry 2005; 50:605-613.

5. Hollingworth SA, Siskind DJ. Anxiolytic, hypnotic and sedative medication use in Australia. Pharmacoepidemiol Drug Saf 2010; 19:280-288.

6. Wolff A, Zuk-Paz L, Kaplan I. Major salivary gland output differs between users and non-users of specific medication categories. Gerodontology 2008; 25:210-216.

7. Hunter KD, Wilson WS. The effects of antidepressant drugs on salivary flow and content of sodium and potassium ions in human parotid saliva. Arch Oral Biol 1995; 40:983-989.

8. Närhi TO, Meurman JH, Ainamo A. Xerostomia and hyposalivation: causes, consequences and treatment in the elderly. Drugs Aging 1999; 15:103-116.

9. de Almeida Pdel V, Gregio AM, Brancher JA, Ignacio SA, Machado MA, de Lima AA et al. Effects of antidepressants and benzodiazepines on stimulated salivary flow rate and biochemistry composition of the saliva. Oral Surg Oral Med Oral Pathol Oral Radiol Endod 2008; 106:58-65.

10. Linjakumpu T, Hartikainen S, Klaukka T, Koponen H, Kivelä SL, Isoaho R. A model to classify the sedative load of drugs. Int J Geriatr Psychiatry 2003; 18:542-544.

11. Lampela P, Hartikainen S, Lavikainen P, Sulkava R, Huupponen R. Effects of medication assessment as part of a comprehensive geriatric assessment on drug use over a 1-year period: a population-based intervention study. Drugs Aging 2010; 27:507-521.

12. Tikkanen P, Nykänen I, Lönnroos E, Sipilä S, Sulkava R, Hartikainen S. Physical Activity at Age of 20-64 Years and Mobility and Muscle Strength in Old Age: A Community-Based Study. Journals of Gerontology.Series A, Biological Sciences \& Medical Sciences 2012; 67:905--910.

13. Syrjälä AM, Raatikainen L, Komulainen K, Knuutila M, Ruoppi P, Hartikainen S et al. Salivary flow rate and periodontal infection: a study among subjects aged 75 years or older. Oral Dis 2011; 17:387-392.

14. Komulainen K, Ylöstalo P, Syrjälä AM, Ruoppi P, Knuutila M, Sulkava R et al. Preference for dentist's home visits among older people. Community Dent Oral Epidemiol 2012; 40:89-95.

15. Navazesh M. Methods for collecting saliva. Ann N Y Acad Sci 1993; 694:72-77. 
16. Flink H, Bergdahl M, Tegelberg A, Rosenblad A, Lagerlof F. Prevalence of hyposalivation in relation to general health, body mass index and remaining teeth in different age groups of adults. Community Dent Oral Epidemiol 2008; 36:523-531.

17. Nederfors T. Xerostomia and hyposalivation. Adv Dent Res 2000; 14:48-56.

18. Taipale HT, Bell JS, Uusi-Kokko M, Lönnroos E, Sulkava R, Hartikainen S. Sedative load among community-dwelling people aged 75 years and older: a population-based study. Drugs Aging 2011; 28:913-925.

19. Lawton MP, Brody EM. Assessment of older people: self-maintaining and instrumental activities of daily living. Gerontologist 1969; 9:179-186.

20. SPSS Inc. SPSS 20.0 for Windows. 2011;20.0.0

21. Nagler RM. Salivary glands and the aging process: mechanistic aspects, health-status and medicinal-efficacy monitoring. Biogerontology 2004; 5:223-233.

22. Loesche WJ, Bromberg J, Terpenning MS, Bretz WA, Dominuquez BL, Grossman NS et al. Xerostomia, xerogenic medications and food avoidances in selected geriatric groups. $J$ Am Geriatr Soc 1995; 43:401-407.

23. Taipale HT, Hartikainen S, Bell JS. A comparison of four methods to quantify the cumulative effect of taking multiple drugs with sedative properties. Am J Geriatr Pharmacother 2010; 8:460 471.

24. Bergdahl M, Bergdahl J. Low unstimulated salivary flow and subjective oral dryness: association with medication, anxiety, depression, and stress. J Dent Res 2000; 79:1652-1658.

25. Hugo FN, Hilgert JB, Corso S, Padilha DM, Bozzetti MC, Bandeira DR et al. Association of chronic stress, depression symptoms and cortisol with low saliva flow in a sample of southBrazilians aged 50 years and older. Gerodontology 2008; 25:18-25.

26. Turner MD, Ship JA. Dry mouth and its effects on the oral health of elderly people. J Am Dent Assoc 2007; 138 (suppl 1):15-20.

27. Dawes C. Salivary flow patterns and the health of hard and soft oral tissues. J Am Dent Assoc 2008; 139 (suppl 2):18-24. 